\title{
Impact of the presence of chronically occluded coronary artery on long-term prognosis of patients with acute ST-segment elevation myocardial infarction
}

\author{
Maciej Lesiak ${ }^{1}$, Monika Cugowska ${ }^{2}$, Aleksander Araszkiewicz ${ }^{1}$, \\ Marek Grygier ${ }^{1}$, Małgorzata Pyda ${ }^{1}$, Włodzimierz Skorupski ${ }^{1}$, \\ Przemysław Mitkowski ${ }^{1}$, Magdalena Łanocha ${ }^{1}$, Stefan Grajek ${ }^{1}$ \\ ${ }^{1} 1^{\text {st }}$ Department of Cardiology, University of Medical Sciences, Poznan, Poland \\ ${ }^{2}$ Swietokrzyskie Cardiology Centre, Kielce, Poland
}

\begin{abstract}
Background: Multivessel disease (MVD) is a significant risk factor in patients with acute ST-segment elevation myocardial infarction (STEMI). Whether the presence of chronic total occlusion (CTO) poses an additional hazard is still unknown. The objective of this study was to evaluate the impact of CTO on survival in STEMI patients.

Methods: The study group consisted of 836 STEMI patients treated with primary percutaneous coronary intervention (PCI). MVD was diagnosed in $52.3 \%$, and CTO in $17.5 \%$ of patients.

Results: In MVD patients, 30-day mortality was 4.8\% (6.8\% in the CTO and $3.8 \%$ in the non-CTO group, $p=0.167)$. After 6 years, of the 437 patients with MVD, $56(38.6 \%)$ died in the CTO group, and $74(25.4 \%)$ in the non-CTO group $(p=0.0055)$. CTO was an independent predictor of long-term mortality (OR 2.07, 95\% CI 1.30-3.28, $p=0.002)$, whereas triple vessel disease was not (OR 1.27, 95\% CI 0.78-1.97, $p=0.358$ ). The other independent predictors of mortality were: age, anterior myocardial infarction, and PCI failure.

Conclusions: The presence of CTO is an independent predictor of the long-term mortality in STEMI patients treated with primary PCI. (Cardiol J 2017; 24, 2: 117-124)
\end{abstract}

Key words: acute myocardial infarction, multivessel disease, chronic total occlusion

\section{Introduction}

In recent years major developments in the treatment of patients with acute ST-segment elevation myocardial infarction (STEMI) have been observed. Rapid restoration of normal blood flow in the infarct-related artery (IRA) with primary angioplasty (percutaneous coronary intervention $[\mathrm{PCI}]$ ) reduces the infarct size, preserves left ventricular function and improves patients' clinical outcome [1]. In the setting of STEMI, the presence of multivessel disease (MVD) is an important risk factor indicating a worse prognosis [2, 3]. According to current guidelines primary PCI procedure is usually limited to IRA, leaving a substantial number of patients with incomplete revascularization [3]. While MVD is widely recognized as a risk factor, it is not clear whether the presence of a chronic total occlusion (CTO) in a non-IRA poses an additional hazard to patients with STEMI. The aim of this study was to assess the impact of MVD, with particular emphasis on CTO, on short and long-term prognosis of patients with STEMI treated with primary PCI.

Address for correspondence: Aleksander Araszkiewicz, MD, PhD, $1^{\text {st }}$ Department of Cardiology, University of Medical Sciences, ul. Długa 1/2, 61-848 Poznań, Poland, tel/fax: +48 6185492 23, e-mail: aaraszkiewicz@interia.pl 


\section{Methods}

Study design, objectives

and patient selection

This study is a part of prospective registry of consecutive patients diagnosed with acute STEMI, treated with primary PCI at University Hospital in Poznan.

Consecutive patients, admitted between October 2001 and December 2003 were enrolled if they met the following inclusion criteria: typical chest pain persisting for more than $30 \mathrm{~min}$ and persistent ST-segment elevation in at least two contiguous leads: $>0.2 \mathrm{mV}$ in leads $\mathrm{V} 2-\mathrm{V} 3$, or $>0.1 \mathrm{mV}$ in other leads, or the presence of a new left bundle branch block. For this analysis patients treated with fibrinolysis prior to PCI were excluded, unconscious patients in cardiogenic shock, those with critical stenosis of the left main coronary artery, as well as patients treated later than $12 \mathrm{~h}$ from symptom onset. The study was performed according to the provisions of the Declaration of Helsinki and good clinical practice. Informed consent was obtained from each patient. The study obtained the approval of local Ethics Committee (protocol no 807A/01).

\section{Procedures and follow-up}

On admission all aspirin, and clopidogrelnaive patients received a loading dose of both drugs, $300 \mathrm{mg}$ each. The primary PCI procedure was performed via femoral approach in accordance with the standards of the time. After femoral puncture, patients were given a bolus of unfractionated heparin in a dose of $100 \mathrm{U} / \mathrm{kg}$. The use of abciximab was at the discretion of the operator. The flow in coronary arteries was assessed by Thrombolysis In Myocardial Infarction (TIMI) scale. Significant stenosis of coronary artery was diagnosed if diameter stenosis was equal to or greater than $70 \%$ by visual estimate. IRA location was diagnosed upon the electrocardiogram (ECG) findings and the typical angiographic image. Single vessel disease (SVD) was diagnosed if significant stenosis was found exclusively in the IRA. MVD was defined as $\geq 70 \%$ diameter stenosis in one or more additional major epicardial vessel or their major branches. A CTO was defined as a non-IRA vessel being completely occluded, with no flow or TIMI 1 flow, and a typical angiographic image of chronically occluded artery. In all patients PCI was limited exclusively to the IRA. Standard catheters and bare metal stents were used during procedures. No aspiration thrombectomy devices were used. The PCI procedure was regarded as successful if final TIMI flow in the IRA was $\geq 2$, with no major complication during the procedure. On discharge all patients were recommended to remain on dual antiplatelet therapy for 12 months, and then lifelong on aspirin alone.

\section{Study end points}

The main outcome measures were 30-day, 12 -month, and 6-year all-cause mortality rate among study patients. Additionally in-hospital, 30 -day, 12-, and 24-month major adverse cardiovascular events were analysed, including death of any cause, cardiovascular death, stroke, recurrent myocardial infarction (MI) (defined as any spontaneous event with persistent ST-segment elevation and/or new Q-wave formation, or the CK-MB rise 3 times above the limit), and target-vessel revascularization. Patient outcomes at 30 days, 12 and 24 months were assessed by direct visits or telephone contact. The long-term all-cause mortality data were obtained from the Polish National Identification Number Registry (PESEL). None of the patients was lost to the long-term follow-up.

\section{Statistical analysis}

All continuous variables are presented as means \pm standard deviation or medians, and were compared using a Student t-test. Categorical variables are presented as counts and percentages or frequencies, and were compared using a $\chi^{2}$ test. Survival curves were plotted using Kaplan-Meier method, and comparisons between groups were done using the log-rank test. The Cox proportionalhazards model was used to identify the independent predictors of mortality. Predictors were selected at $\mathrm{p}<0.1$ in univariate analysis. The significant factors were calculated and expressed as adjusted hazard ratio (HR), with 95\% confidence interval (CI). All probability values $<0.05$ were considered significant. Statistical analysis was performed using the statistical package STATISTICA 8.1 PL.

\section{Results}

\section{Patient population}

Between October 2001 and December 2003 a total of 1070 STEMI patients were admitted to the aforementioned department and treated with primary PCI. Of those, 836 met all the inclusion/ /exclusion criteria and constitute this study group. The baseline demographics and clinical characteristics of the entire population is presented in Table 1. Table 2 summarizes lesion and procedural characteristics of the overall group. 
Table 1. Baseline demographics and clinical characteristics of the overall study group $(n=836)$.

\begin{tabular}{lc}
\hline Variable & Patient-based \\
\hline Age [years] & $61.3 \pm 11.7$ \\
Male & $602(72 \%)$ \\
Previous MI & $165(19.7 \%)$ \\
Hypertension & $454(54.3 \%)$ \\
Diabetes & $135(16.1 \%)$ \\
Current smoker & $472(56.5 \%)$ \\
Peripheral vessel disease & $79(9.4 \%)$ \\
History of PCl/CABG & $47(5.6 \%) / 12(1.4 \%)$ \\
\hline
\end{tabular}

CABG - coronary artery bypass grafting; $\mathrm{Ml}$ - myocardial infarction; $\mathrm{PCl}$ - percutaneous coronary intervention.

Table 2. Procedural characteristics of the overall study group $(\mathrm{n}=836)$.

\begin{tabular}{lc}
\hline Variable & Patient-based \\
\hline IRA & \\
LAD & $382(45.7 \%)$ \\
LCX & $109(13.0 \%)$ \\
RCA & $345(41.3 \%)$ \\
MVD & $437(52.3 \%)$ \\
CTO & $146(17.5 \%)$ \\
CTO LAD & $40(4.8 \%)$ \\
CTO LCX & $49(5.8 \%)$ \\
CTO RCA & $57(6.8 \%)$ \\
IRA final TIMI flow $\geq 2$ & $791(94.6 \%)$ \\
\hline
\end{tabular}

CTO - chronic total occlusion; IRA - infarct-related artery; LAD - left anterior descending; LCX - left circumflex; MVD - multivessel disease; RCA — right coronary artery; TIMI - Thrombolysis In Myocardial Infarction

Table 3. Multivariate Cox proportional hazards analysis of long-term mortality of the overall study group $(\mathrm{n}=836)$.

\begin{tabular}{lccc}
\hline Variable & OR & $95 \% \mathrm{Cl}$ & $\mathbf{P}$ \\
\hline Age & 1.06 & $1.04-1.08$ & $<0.0001$ \\
$\begin{array}{l}\text { Chronic total } \\
\text { occlusion }\end{array}$ & 2.41 & $1.59-3.63$ & $<0.0001$ \\
PCl failure & 3.42 & $1.68-6.97$ & 0.0006 \\
$\begin{array}{l}\text { Multivessel } \\
\text { disease }\end{array}$ & 1.39 & $0.93-2.09$ & 0.103 \\
Anterior MI & 1.41 & $0.99-2.01$ & 0.052 \\
\hline
\end{tabular}

$\mathrm{Cl}$ - confidence interval; $\mathrm{MI}$ - myocardial infarction; OR — odds ratio; $\mathrm{PCl}$ - percutaneous coronary intervention
On baseline coronary angiography SVD was diagnosed in $399(47.7 \%)$ patients, and MVD in 437 (52.3\%), of whom 262 had double-, and 175 triple-vessel disease $(31.3 \%$ and $20.9 \%$, respectively). The presence of chronically occluded non-IRA was found in 146 patients. Final TIMI flow $\geq 2$ was achieved in $791(94.6 \%)$ patients. Thirty-day, and 12 -month mortality rate was 31 $(3.7 \%)$, and $65(7.8 \%)$, respectively. Within the first 12 months recurrent MI occurred in 47 (5.6\%) patients, stroke in $15(1.8 \%)$, and target-vessel revascularization in 72 (8.6\%). Additionally, 155 (18.5\%) patients underwent repeated PCI of noninfarct-related vessel. Surgical revascularization (coronary artery bypass grafting [CABG]) was performed in $17(2 \%)$ patients. The mean and the median time of observation time was $74 \pm 27$ and 83 months, respectively. During this time 193 $(23.1 \%)$ patients died - $63(15.8 \%)$ in SVD group, and $130(29.7 \%)$ in MVD group, $\mathrm{p}<0.0001$. The following risk factors correlated significantly with all-cause mortality: age (OR 1.06, 95\% CI 1.04-1.0, $\mathrm{p}<0.0001)$, history of MI (1.6, 95\% CI 1.14-2.43, $\mathrm{p}=0.008)$, diabetes mellitus (OR 1.64, 95\% CI $1.09-2.47, \mathrm{p}=0.016)$, the presence of MVD (OR $2.25,95 \%$ CI $1.60-3.16, \mathrm{p}<0.0001$ ), CTO (OR $2.51,95 \%$ CI $1.71-3.68, \mathrm{p}<0.0001)$, and PCI failure (OR 4.23, 95\% CI 2.20-8.14, $\mathrm{p}<0.0001$ ). Anterior location of MI has shown borderline significance (OR 1.34, 95\% CI 0.97-1.85, $\mathrm{p}=0.072$ ). In multivariate analysis diabetes mellitus, previous MI, and the presence of MVD were no longer significant predictors of death, and only the age, CTO and PCI failure remained significant (Table 3 ). Kaplan-Meier survival curves of patients with SVD, and MVD with or without the presence of CTO are presented in Figure 1.

Results of multivariate analyses are presented in Table 4. The presence of CTO was not an independent predictor of short-term mortality. Nevertheless, the longer the observation time, the greater the predictive value of CTO. Importantly, a similar relationship could not be found for the presence of MVD, which per se did not correlate with mortality during any observation time.

\section{Analysis of patients with MVD}

Of 437 patients with MVD in 146 the presence of CTO was found. Patients in the CTO group, as compared non-CTO group, had a significantly more frequent history of MI and PCI procedure, signifi- 


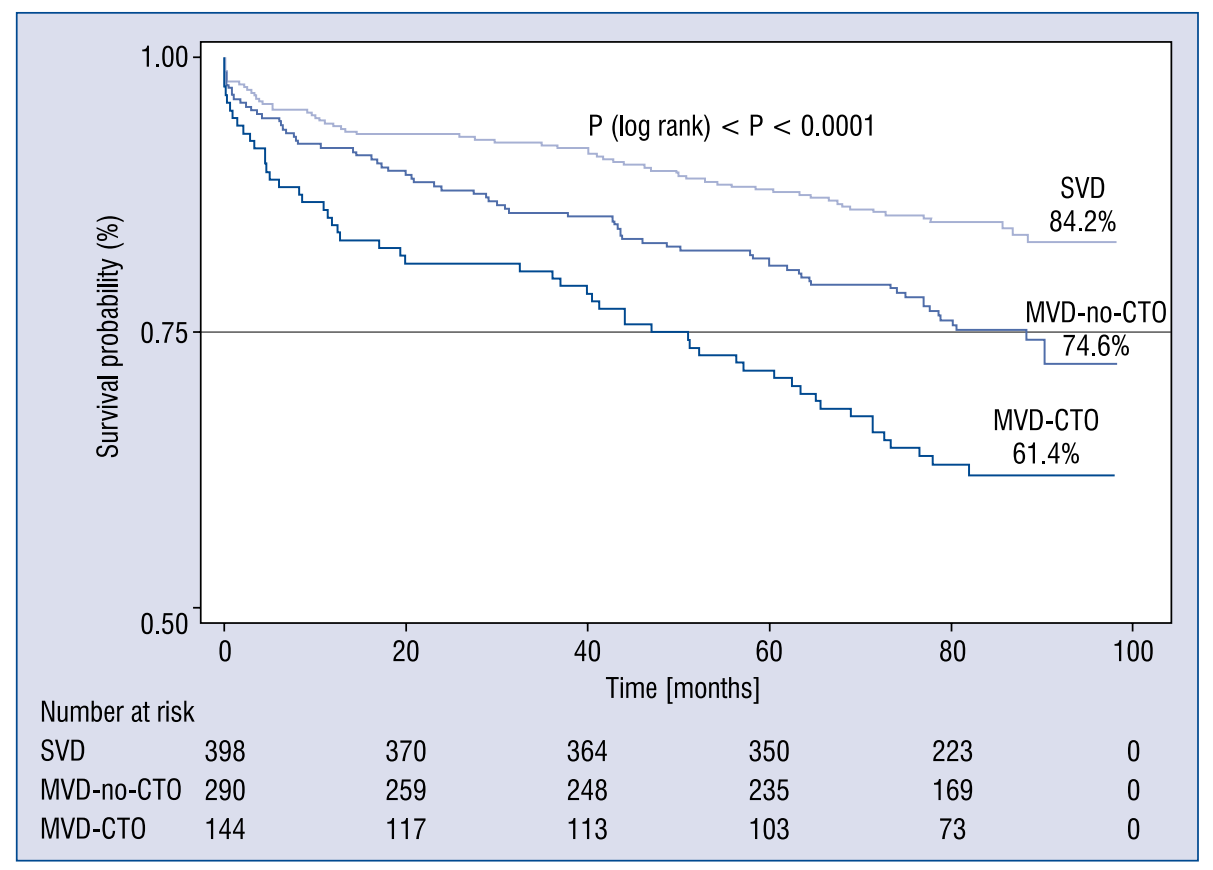

Figure 1. Kaplan-Meier survival curves of patients with single, and multivessel disease (MVD) with and without the presence of chronic total occlusion (CTO); SVD — single vessel disease.

Table 4. Multivariate Cox proportional hazards analysis of all-cause mortality in subsequent periods of observation in the whole group $(n=836)$.

\begin{tabular}{llccccc}
\hline Observation time & & Age & PCl failure & CTO & MVD & Anterior MI \\
\hline \multirow{3}{*}{30 days } & OR & 1.06 & 2.07 & 2.18 & 1.23 & 1.69 \\
& $95 \% \mathrm{Cl}$ & $1.02-1.10$ & $0.64-6.71$ & $0.85-5.58$ & $0.50-3.05$ & $0.79-3.60$ \\
& $\mathrm{p}$ & 0.0003 & 0.222 & 0.103 & 0.640 & 0.171 \\
12 months & OR & 1.04 & 3.75 & 2.22 & 1.11 & 2.23 \\
& $95 \% \mathrm{Cl}$ & $1.02-1.07$ & $1.64-8.58$ & $1.21-4.08$ & $0.58-2.14$ & $1.28-3.87$ \\
& $\mathrm{p}$ & 0.0001 & 0.002 & 0.009 & 0.737 & 0.004 \\
24 months & OR & 1.05 & 3.26 & 2.26 & 1.1 & 2.17 \\
& $95 \% \mathrm{Cl}$ & $1.03-1.08$ & $1.50-7.09$ & $1.34-3.82$ & $0.63-1.92$ & $1.35-3.49$ \\
& $\mathrm{p}$ & $<0.0001$ & 0.003 & 0.002 & 0.715 & 0.001 \\
6 years & OR & 1.06 & 3.42 & 2.41 & 1.39 & 1.33 \\
& $95 \% \mathrm{Cl}$ & $1.03-1.06$ & $2.2-3.12$ & $1.35-2.05$ & $0.93-2.09$ & $0.99-2.01$ \\
& $\mathrm{p}$ & $<0.0001$ & 0.0006 & $<0.0001$ & 0.103 & 0.052 \\
\hline
\end{tabular}

$\mathrm{Cl}$ - confidence interval; CTO — chronic total occlusion; $\mathrm{MI}$ - myocardial infarction; MVD — multivessel disease; OR — odds ratio; $\mathrm{PCl}$ - percutaneous coronary intervention

cantly less often anterior location of MI, as well they were more likely to have diabetes, although this difference was not statistically significant. TIMI flow $\geq 2$ was achieved in $92.4 \%$ of patients with MVD; $93.5 \%$ in non-CTO vs. $90.4 \%$ in the CTO group $(\mathrm{p}=0.177)$, whereas TIMI 3 flow was achieved in $87.6 \%$ of non-CTO patients and in $84.2 \%$ of the CTO patients $(\mathrm{p}=0.210)$ (Table 5$)$.

Thirty-day mortality rate of MVD cohort was $4.8 \%$ (21 patients). The rate of death in the CTO group was almost double the rate of the non-CTO group $(6.8 \%$ vs. $3.8 \%)$, although this difference 
Table 5. Baseline demographics and clinical characteristics of patients with multivessel disease (MVD) $(n=437)$

\begin{tabular}{lcccc}
\hline & $\begin{array}{c}\text { Total MVD } \\
(\mathbf{n}=\mathbf{4 3 7 )}\end{array}$ & $\begin{array}{c}\text { Non-CTO group } \\
(\mathbf{n}=291)\end{array}$ & $\begin{array}{c}\text { CTO group } \\
(\mathbf{n}=146)\end{array}$ & $\begin{array}{c}\text { P } \\
\text { (non-CTO vs. CTO) }\end{array}$ \\
\hline Age [years] & $63.1 \pm 11.7$ & $63.6 \pm 11.3$ & $62.5 \pm 11.2$ & 0.335 \\
Previous MI & $116(26.5 \%)$ & $56(19.2 \%)$ & $60(41.1 \%)$ & $<0.0001$ \\
History of PCl & $28(6.4 \%)$ & $9(3.1 \%)$ & $19(13.0 \%)$ & 0.0001 \\
Diabetes & $92(21.1 \%)$ & $54(18.6 \%)$ & $38(26.0 \%)$ & 0.074 \\
Current smoker & $235(57.8 \%)$ & $151(51.9 \%)$ & $84(57.5 \%)$ & 0.269 \\
Hypertension & $252(57.7 \%)$ & $168(57.7 \%)$ & $84(57.5 \%)$ & 0.968 \\
Anterior MI & $195(44.6 \%)$ & $136(46.7 \%)$ & $59(33.8 \%)$ & 0.011 \\
Final TIMI flow $\geq 2$ & $404(92.4 \%)$ & $272(93.5 \%)$ & $132(90.4 \%)$ & 0.177 \\
\hline
\end{tabular}

СТО — chronic total occlusion; $\mathrm{MI}$ - myocardial infarction; $\mathrm{PCl}$ - percutaneous coronary intervention; TIMI — Thrombolysis In Myocardial Infarction

Table 6. Multivariate Cox proportional hazards analysis of all-cause mortality in subsequent periods of observation in patients with multivessel disease $(n=437)$.

\begin{tabular}{|c|c|c|c|c|c|c|}
\hline \multicolumn{2}{|c|}{ Observation time } & \multirow{2}{*}{$\begin{array}{l}\text { Age } \\
1.07\end{array}$} & \multirow{2}{*}{$\begin{array}{c}\mathrm{PCl} \text { failure } \\
1.85\end{array}$} & \multirow{2}{*}{$\begin{array}{l}\text { СТО } \\
1.88\end{array}$} & \multirow{2}{*}{$\begin{array}{l}3 \text { VD } \\
2.39\end{array}$} & \multirow{2}{*}{$\begin{array}{c}\text { Anterior MI } \\
1.43\end{array}$} \\
\hline 30 days & OR & & & & & \\
\hline & $95 \% \mathrm{Cl}$ & $1.01-1.11$ & $0.45-7.52$ & $0.70-5.03$ & $0.88-6.47$ & $0.80-3.21$ \\
\hline & $\mathrm{p}$ & 0.005 & 0.384 & 0.202 & 0.085 & 0.325 \\
\hline \multirow[t]{3}{*}{12 months } & OR & 1.03 & 4.38 & 1.88 & 2.16 & 1.55 \\
\hline & $95 \% \mathrm{Cl}$ & $1.00-1.06$ & $1.77-10.84$ & $0.96-3.65$ & $1.09-4.26$ & $0.83-2.91$ \\
\hline & $\mathrm{p}$ & 0.041 & 0.001 & 0.061 & 0.026 & 0.165 \\
\hline \multirow[t]{3}{*}{24 months } & OR & 1.05 & 4.02 & 2.06 & 1.32 & 1.88 \\
\hline & $95 \% \mathrm{Cl}$ & $1.02-1.08$ & $1.69-9.56$ & $1.15-3.71$ & $0.72-2.40$ & $1.05-3.36$ \\
\hline & $\mathrm{p}$ & $<0.0001$ & 0.001 & 0.015 & 0.355 & 0.032 \\
\hline \multirow[t]{3}{*}{6 years } & OR & 1.06 & 3.48 & 2.07 & 1.24 & 1.57 \\
\hline & $95 \% \mathrm{Cl}$ & $1.03-1.08$ & $1.52-7.98$ & $1.30-3.28$ & $0.78-1.97$ & $1.00-2.44$ \\
\hline & $\mathrm{p}$ & $<0.0001$ & 0.003 & 0.045 & 0.358 & 0.045 \\
\hline
\end{tabular}

$\mathrm{Cl}$ - confidence interval; CTO - chronic total occlusion; $\mathrm{MI}$ - myocardial infarction OR - odds ratio; 3VD - triple vessel disease; $\mathrm{PCl}$ - percutaneous coronary intervention

was not statistically significant $(p=0.167)$. In a multivariate analysis only patient age was an independent predictor of 30-day mortality (OR 1.07, $95 \%$ CI 1.01-1.11, $\mathrm{p}=0.005)$.

After 1 year total, cardiac mortality rate was $11 \%$ (48 patients), and $10 \%$ (44 patients), respectively. Both total and cardiac mortality were significantly higher in the CTO group: for cardiac mortality $22(15.1 \%)$ vs. $22(7.6 \%), \mathrm{p}=0.015$, for all-cause mortality $23(15.8 \%)$ vs. 25 (8.6\%), $\mathrm{p}=0.026$. After 6 years $129(29.7 \%)$ patients died, of whom 56 (38.6\%) in the CTO group, and $74(25.4 \%)$ in the non-CTO group ( $\mathrm{p}=0.0055)$.

In univariate analysis we found the following significant risk factors of long-term all-cause mor- tality: patient's age (OR 1.05, 95\% CI 1.02-1.08, $\mathrm{p}=0.0001)$, the presence of triple-vessel disease (OR 1.63, 95\% CI 1.07-2.48, $\mathrm{p}=0.019$ ), CTO (OR $1.82,95 \%$ CI $1.19-2.82, \mathrm{p}=0.005)$, and PCI failure (OR 3.69, 95\% 1.70-8.00 CI, $\mathrm{p}=0.0008$ ). Anterior location of MI has shown borderline significance (OR 1.42, 95\% CI 0.94-2.15, $\mathrm{p}=0.093$ ). Results of multivariate analysis in subsequent periods of observation are presented in Table 6 . The presence of CTO was not an independent predictor of short-term mortality. Nevertheless, the longer the observation time, the greater the predictive value of CTO. It is important to note, a similar relationship could not be found for the presence of triplevessel disease, which proved to be an independent 
predictor of death only at 12 months. In a long-term follow-up, the significant independent predictors of all-cause mortality were patients' age, anterior location of MI, PCI failure and the presence of CTO.

\section{Discussion}

Long-term clinical outcomes of a large cohort of STEMI patients treated with primary PCI were reported on. The main objective of the study was to determine the effect and the the extent of coronary artery disease, particularly the presence of CTO, on early and long-term survival.

There were risk factors of early and late mortality such as age, presence of MVD, CTO, anterior location of MI, and PCI failure. The main reason of the failure of PCI was due to slow- or no-flow in IRA. All the procedures were performed in the early years of this century, thus no thrombectomy devices were used at that time. In cases where suboptimal flow was obtained bailout intracoronary abciximab injections were usually performed, sometimes in combination with verapamil, nitroprusside or adenosine. In later years, a new strategy was introduced using upfront high-dose intracoronary adenosine injections with more promising results [4]. MVD is a well-known risk factor in the death of patients with STEMI $[2,3]$. Whether the presence of CTO plays an independent role is still a matter of debate. The present study group was not at high risk. In order to eliminate the impact of other powerful risk factors, the following patients were excluded: patients those in a coma, with cardiogenic shock, significant left main stenosis, as well as those of whom reperfusion was achieved after $12 \mathrm{~h}$ from symptom onset. This resulted in a low 30-day mortality rate for the entire group (3.7\%). This study, like many others, found that MVD was an important risk factor of death in patients with STEMI. However, after taking into account the presence of CTO, the mere presence of MVD was no longer an independent predictor, nor was the presence of triple-vessel disease. Interestingly, the predicting power of CTO grew along with time. In the early period, most likely due to relatively low risk for the whole group, CTO had negligible or borderline impact on survival. Over the years, its relevance grew, being a very strong predictor of death after 6 years. Many recent papers pointed to the importance of CTO in patients with STEMI. van der Schaaf et al. [5], in a 1-year observation of 1417 patients with STEMI reported that the presence of CTO was an independent risk factor of mortality, while the mere presence of MVD was not. What's more, the mortality rate of patients with MVD but without CTO was comparable with the mortality of patients with SVD. The same conclusion could be drawn when looking at the Figure 1 presented in this study. The survival curves of SVD patients, and patients with non-CTO MVD run initially very close to each other, and begin to separate only after 2 years. In a later study of the same group the authors evaluated the effects of CTO on long-term prognosis [6]. They also found that the presence of CTO, but not MVD alone, was associated with long-term mortality, even when early deaths were excluded from the analysis. Polish authors, in a population of 666 STEMI patients with MVD, after 5 years of observation discovered that CTO was an independent predictor of mortality [7]. Importantly, the study group was a high risk one. On admission shock was diagnosed in $22 \%$ of CTO patients, whereas in those with non-CTO MVD in 11\% ( $\mathrm{p}=0.0027)$. The CTO group had significantly worse TIMI flow after procedure, and significantly higher in-hospital mortality rate than the rest of the MVD group (21\% vs. $6.3 \%, \mathrm{p}<0.0001)$. After 5 years mortality rate in the CTO group was almost twice as high as in the non-CTO patients with MVD (40\% vs. $22 \%$, $\mathrm{p}<0.0001)$. Similar results have been reported by a Japanese group for a population of 417 patients with STEMI treated with primary PCI within $24 \mathrm{~h}$ from symptom onset [8]. The presence of CTO, (found in only $8 \%$ of patients), as in the previous analysis, was associated with a higher incidence of shock (25\% vs. $11 \%$, p < 0.05). Again, 30-day mortality rate was significantly higher in the CTO group (14.3\% vs. $3.4 \%, \mathrm{p}<0.01)$. In the present population the presence CTO was found in $17 \%$ of all patients, and $33 \%$ of the MVD group. Knowing the results of previous studies, high-risk subjects were deliberately excluded to reduce the impact of other powerful predictors of mortality. Most likely that was the reason no independent effect of CTO could bedemonstrated on in-hospital and 30-day mortality, although among patients with MVD 30-day mortality rate in the CTO group was almost twice as high as those without CTO $(6.8 \%$ vs. $3.8 \%, p=0.167)$. Studies that also included patients in cardiogenic shock reported significantly higher early mortality in CTO group [7, 8]. In this study however, each subsequent observation period the significance of CTO as a predictor grew, and after 1 year cardiac mortality was significantly higher in this group ( $15.1 \%$ vs. $7.6 \%, \mathrm{p}=0.015)$. Since then, the presence of CTO became an independent risk factor of mortality, with a much 
stronger impact on survival than the mere presence of MVD, which no longer played an independent role in patient outcome.

This raises the question about the possible mechanisms responsible for a poorer prognosis of patients with STEMI and concomitant presence of CTO. In the acute phase of STEMI the lack of sufficient collateral circulation to the IRA from the donor vessel being chronically occluded may play a significant role. This explains the higher incidence of cardiogenic shock in this group of patients, described in the above-cited papers [6,7]. In addition, as demonstrated in the present group, CTO patients are more likely to have a history of previous MI, hence poorer left ventricular function, which is one of the major predictors of poor prognosis $[8,9]$. Moreover, prior to the index MI, IRA might have been a donor artery of collateral circulation to the myocardium supplied by the CTO vessel. Even after successful primary PCI, due to the damage of microvascular circulation, the collateral flow to this area may be permanently impaired $[9,10]$. The question remains whether the results of this and other studies justify routine treatment aimed at complete revascularization, including the opening of chronically occluded arteries in STEMI patients. Since the current guidelines were released, the PRAMI and CvLPRIT trials have shown improved outcomes with a comprehensive approach [11, 12]. This question is even more problematic regarding CTO lesions. During the 80s and 90s of the last century, due to the limited success rate of PCI procedures, majority of CTO lesions were left untreated or alternatively patients with MVD were referred to CABG. In recent years, owing to major developments in PCI techniques, significant improvement in outcomes of recanalization procedures has been observed. In experienced centres the reported success rate is close to $90 \%[13,14]$. Multiple studies support the benefit of opening a CTO with regard to symptom relief [15]. Recovery of left ventricular function has also been reported, but this effect strongly depends on the presence of viable myocardium $[16,17]$. Finally, increasingly more studies provide data on the role of CTO as an predictor of sudden cardiac death, and long-term mortality [18]. In a recent meta-analysis of 23 observational studies, Khan et al. [19]. found that successful recanalization of a CTO resulted in improved all-cause mortality, and lower rates of major adverse cardiac events. One of the possible explanations may be the favourable antiarrhythmic effect of successful recanalization of CTO. In recently published paper Cetin et al. [20] demonstrat- ed that after successful opening of the occluded vessel, ECG markers of ventricular repolarization inhomogeneity significantly improved, as compared with the pre-PCI values. Lee et al. [21] reported that in 60 out of 88 patients with CTO, in whom an attempt of PCI was made after the acute phase of MI, the procedure was successful in $40(67 \%)$ patients. There were no deaths during follow-up in this successful group, while in patients in whom PCI failed or was not attempted death occurred in $23 \%(\mathrm{p}=0.001)$. Thus, it may be concluded that the results of thisstudy add one more premise to the general agreement that each STEMI patient with CTO in non-culprit vessel should be considered for future procedures to ensure completeness of revascularization. In the present study 155 patients with MVD underwent PCI of vessel other than an IRA (18.5\%) during the first year. Unfortunately, accurate data on how many recanalization attempts were made and what was the outcome of these procedures was not available

\section{Limitations of the study}

A major limitation of the study is that it was a non-randomized, observational, single centre design. The study patients were treated many years ago with techniques not recommended under current guidelines. Only bare metal stents were implanted and no aspiration thrombectomy devices were used during procedures. Another limitation of the study is the lack of data on left ventricular function, both on admission and after discharge from the hospital. The angiograms were not reviewed by a central angiographic core lab. Not all of the endpoints could be assessed and confirmed by direct visits; some of them were obtained by telephone contact. We do not know how many PCI procedures performed during the observation time concerned CTO vessels, and what the success rate was.

\section{Conclusions}

The presence of CTO is an independent predictor of the long-term mortality in STEMI patients treated with primary PCI. The longer the observation time the more significant the impact of CTO has on survival.

The paper carries additional information on the importance of the presence of CTO in patients with coronary artery disease, and particularly with STEMI. In recent years, a major development in PCI techniques have been observed, especially regarding CTO procedures. This should prompt clinicians to carefully make evaluations of all 
STEMI patients with regard to the indications of complete revascularization including chronically occluded vessels.

\section{Conflict of interest: None declared}

\section{References}

1. Keeley EC, Boura JA, Grines CL. Primary angioplasty versus intravenous thrombolytic therapy for acute myocardial infarction: a quantitative review of 23 randomised trials. Lancet. 2003; 361(9351): 13-20, doi: 10.1016/S0140-6736(03)12113-7, indexed in Pubmed: 12517460.

2. De Luca G, Suryapranata H, van ,t Hof AWJ, et al. Prognostic assessment of patients with acute myocardial infarction treated with primary angioplasty: implications for early discharge. Circulation. 2004; 109(22): 2737-2743, doi: 10.1161/01. CIR.0000131765.73959.87, indexed in Pubmed: 15159293.

3. Steg PhG, James SK, Atar D, et al. Task Force on the management of ST-segment elevation acute myocardial infarction of the European Society of Cardiology (ESC). ESC Guidelines for the management of acute myocardial infarction in patients presenting with ST-segment elevation. Eur Heart J. 2012; 33(20): 2569-2619, doi: 10.1093/eurheartj/ehs215, indexed in Pubmed: 22922416.

4. Grygier M, Araszkiewicz A, Lesiak M, et al. New method of intracoronary adenosine injection to prevent microvascular reperfusion injury in patients with acute myocardial infarction undergoing percutaneous coronary intervention. Am J Cardiol. 2011; 107(8): 1131-1135, doi: 10.1016/j.amjcard.2010.12.010, indexed in Pubmed: 21310372.

5. van der Schaaf RJ, Vis MM, Sjauw KD, et al. Impact of multivessel coronary disease on long-term mortality in patients with ST-elevation myocardial infarction is due to the presence of a chronic total occlusion. Am J Cardiol. 2006; 98(9): 1165-1169, doi: 10.1016/j.amjcard.2006.06.010, indexed in Pubmed: 17056319.

6. Claessen BE, van der Schaaf RJ, Verouden NJ, et al. Evaluation of the effect of a concurrent chronic total occlusion on long-term mortality and left ventricular function in patients after primary percutaneous coronary intervention. JACC Cardiovasc Interv. 2009; 2(11): 1128-1134, doi: 10.1016/j.jcin.2009.08.024, indexed in Pubmed: 19926056.

7. Tajstra M, Gasior M, Gierlotka M, et al. Comparison of five-year outcomes of patients with and without chronic total occlusion of noninfarct coronary artery after primary coronary intervention for ST-segment elevation acute myocardial infarction. Am J Cardiol. 2012; 109(2): 208-213, doi: 10.1016/j.amjcard.2011.08.026, indexed in Pubmed: 21996144.

8. Mizuguchi Y, Takahashi A, Yamada T, et al. Chronic total occlusion in a non-infarct-related coronary artery exacerbates prognosis in acute myocardial infarction: a Japanese single-center retrospective study. Int J Cardiol. 2014; 176(3): 1139-1141, doi: 10.1016/j.ijcard.2014.07.286, indexed in Pubmed: 25147073.

9. Bolognese L, Carrabba N, Parodi G, et al. Impact of microvascular dysfunction on left ventricular remodeling and long-term clinical outcome after primary coronary angioplasty for acute myocardial infarction. Circulation. 2004; 109(9): 1121-1126, doi: 10.1161/01. CIR.0000118496.44135.A7, indexed in Pubmed: 14967718.
10. Araszkiewicz A, Lesiak M, Grajek S, et al. Effect of microvascular reperfusion on prognosis and left ventricular function in anterior wall myocardial infarction treated with primary angioplasty. Int J Cardiol. 2007; 114(2): 183-187, doi: 10.1016/j. ijcard.2006.01.057, indexed in Pubmed: 16793152.

11. Wald DS, Morris JK, Wald NJ, et al. PRAMI Investigators. Randomized trial of preventive angioplasty in myocardial infarction. N Engl J Med. 2013; 369(12): 1115-1123, doi: 10.1056/NEJMoa1305520, indexed in Pubmed: 23991625.

12. Gershlick AH, Khan JN, Kelly DJ, et al. Randomized trial of complete versus lesion-only revascularization in patients undergoing primary percutaneous coronary intervention for STEMI and multivessel disease: the CvLPRIT trial. J Am Coll Cardiol. 2015; 65(10): 963-972, doi: 10.1016/j.jacc.2014.12.038, indexed in Pubmed: 25766941.

13. Patel VG, Michael TT, Mogabgab O, et al. Clinical, angiographic, and procedural predictors of periprocedural complications during chronic total occlusion percutaneous coronary intervention. J Invasive Cardiol. 2014; 26(3): 100-105, indexed in Pubmed: 24610502 .

14. El Sabbagh A, Patel VG, Jeroudi OM, et al. Angiographic success and procedural complications in patients undergoing retrograde percutaneous coronary chronic total occlusion interventions: a weighted meta-analysis of 3,482 patients from 26 studies. Int J Cardiol. 2014; 174(2): 243-248, doi: 10.1016/j.ijcard.2014.04.004, indexed in Pubmed: 24768461.

15. Joyal D, Afilalo J, Rinfret S. Effectiveness of recanalization of chronic total occlusions: a systematic review and metaanalysis. Am Heart J. 2010; 160(1): 179-187, doi: 10.1016/j. ahj.2010.04.015, indexed in Pubmed: 20598990.

16. Allman KC, Shaw LJ, Hachamovitch R, et al. Myocardial viability testing and impact of revascularization on prognosis in patients with coronary artery disease and left ventricular dysfunction: a meta-analysis. J Am Coll Cardiol. 2002; 39(7): 1151-1158, indexed in Pubmed: 11923039.

17. Baks T, van Geuns RJ, Duncker DJ, et al. Prediction of left ventricular function after drug-eluting stent implantation for chronic total coronary occlusions. J Am Coll Cardiol. 2006; 47(4): 721-725, doi: 10.1016/j.jacc.2005.10.042, indexed in Pubmed: 16487835 .

18. Godino C, Bassanelli G, Economou FI, et al. Predictors of cardiac death in patients with coronary chronic total occlusion not revascularized by PCI. Int J Cardiol. 2013; 168(2): 1402-1409, doi: 10.1016/j.ijcard.2012.12.044, indexed in Pubmed: 23317549.

19. Khan MF, Wendel CS, Thai HM, et al. Effects of percutaneous revascularization of chronic total occlusions on clinical outcomes: a meta-analysis comparing successful versus failed percutaneous intervention for chronic total occlusion. Catheter Cardiovasc Interv. 2013; 82(1): 95-107, doi: 10.1002/ccd.24863, indexed in Pubmed: 23413111.

20. Cetin M, Zencir C, Cakici M, et al. Effect of a successful percutaneous coronary intervention for chronic total occlusion on parameters of ventricular repolarization. Coron Artery Dis. 2014; 25(8): 705-712, doi: 10.1097/MCA.0000000000000138, indexed in Pubmed: 25009975.

21. Lee JuH, Park HS, Ryu HM, et al. Impact of multivessel coronary disease with chronic total occlusion on one-year mortality in patients with acute myocardial infarction. Korean Circ J. 2012; 42(2): 95-99, doi: 10.4070/kcj.2012.42.2.95, indexed in Pubmed: 22396696. 